\title{
Rabbit Aortic Smooth Muscle Cells Express Inducible Macrophage Scavenger Receptor Messenger RNA That Is Absent from Endothelial Cells
}

\author{
Perry E. Bickel and Mason W. Freeman \\ Department of Medicine, Endocrine Unit, Massachusetts General Hospital and Harvard Medical School, Boston, Massachusetts 02114
}

\begin{abstract}
Scavenger receptors mediate uptake of modified low density lipoproteins by macrophages. The accumulation of lipids via this process is thought to lead to foam cell formation in developing atherosclerotic plaques. Smooth muscle cells, which can also be converted to foam cells in vivo, have not been shown to express the same scavenger receptor previously cloned in macrophages. We report the cloning of two cDNAs that encode type I and type II scavenger receptors isolated from rabbit smooth muscle cells. The deduced protein sequences of these isolates are highly homologous to the scavenger receptors previously isolated from macrophages. Treatment of smooth muscle cells with phorbol esters induced a marked increase in scavenger receptor mRNA and a fivefold increase in receptor degradation activity. Rabbit venous endothelial cells in primary culture and a bovine aortic endothelial cell line had no detectable scavenger receptor mRNA, despite having scavenger receptor degradation activity. The latter finding suggests that endothelial cells may possess a scavenger receptor which is structurally distinct from that found in macrophages and smooth muscle cells. The isolation of cDNAs encoding the rabbit scavenger receptor should prove useful for in vitro and in vivo studies that employ the rabbit as a model of human atherosclerosis. ( $J$. Clin. Invest. 1992.90:1450-1457.) Key words: acetylated LDL - endothelial cells • foam cells • oxidized LDL • scavenger receptor
\end{abstract}

\section{Introduction}

The appearance of lipid-laden macrophages and smooth muscle cells ( $\mathrm{SMC}^{1}$; foam cells) in the intimal segment of the artery wall is one of the earliest histologic changes noted in developing atherosclerotic plaques (1-4). Studies by Goldstein, Brown, et al. demonstrated that the in vitro binding of native low density lipoproteins (LDL) to cells expressing the LDL receptor did not result in foam cell formation (5-7). These observations resulted in the identification of a new receptor that could mediate this transformation in macrophages. Ini-

Address reprint requests to Dr. Freeman, Bulfinch Building, Massachusetts General Hospital, Boston, MA 02114.

Received for publication 11 February 1992 and in revised form 29 April 1992

1. Abbreviations used in this paper: AcLDL, acetylated LDL; OxLDL, oxidized LDL; PCR, polymerase chain reaction; SMC, smooth muscle cell; SR, scavenger receptor.

J. Clin. Invest.

(c) The American Society for Clinical Investigation, Inc.

$0021-9738 / 92 / 10 / 1450 / 08 \quad \$ 2.00$

Volume 90 , October 1992, 1450-1457 tially termed the acetyl-LDL receptor or scavenger receptor (SR), this membrane protein was shown to bind chemically modified forms of LDL. The expression of this receptor was initially reported to be limited to cells of the reticuloendothelial system, with the highest levels of modified LDL uptake and degradation seen in macrophages (5-7). The failure to detect significant SR degradation activity in SMC led to the proposal of an alternative mechanism by which this cell type might be converted into foam cells (8).

The discovery that SR ligands, particularly oxidized LDL (OxLDL), are found in human and rabbit atherosclerotic plaques ( 9 ) indicated that these early in vitro observations on the conversion of macrophages into foam cells might be quite relevant to the in vivo process. Studies of the binding of OxLDL and acetylated LDL (AcLDL) to cells in culture have suggested, however, that a single receptor cannot account for all observed interactions (10-12). In addition, in situ clearance studies of perfused, radiolabeled SR ligands have also demonstrated differences among SRs in their ligand affinity and tissue localization (13-15). These investigations have prompted speculation that multiple SRs may exist, including one receptor for AcLDL, another receptor for OxLDL, and a third receptor that has the capacity to bind both ligands.

The AcLDL receptor has recently been cloned from bovine, human, and murine macrophage sources (16-19). Two cDNAs, encoding a type I receptor and a shorter type II receptor, have been identified in all three species. Both receptor cDNAs, when transiently transfected into COS cells, bind AcLDL with high affinity. The cloned bovine receptor cDNAs, when permanently transfected into Chinese hamster ovary (CHO) cells, have been shown to bind both Ox- and AcLDL in a high-affinity and saturable interaction (20). These cloned receptors were also shown to mediate lipid accumulation in $\mathrm{CHO}$ cells in a manner reminiscent of macrophage foam cell formation. While AcLDL fully competed for the binding of OxLDL to the transfected SRs, OxLDL did not fully compete in a reciprocal manner for the binding of AcLDL to the same transfected receptors. This nonreciprocal cross-competition of Ac- and OxLDL for the transfected SRs mimics properties described in some macrophage cell lines and some endothelial cell lines, but it differs from the receptor activity reported in others (10-12). Specifically, there is no evidence that the transfected SRs have a binding site that only recognizes OxLDL, as has been demonstrated in mouse peritoneal macrophages $(10$, 11). No qualitative differences in binding behavior between transfected type I and type II SRs have been noted that could account for the differences found in studies of native cells. Cotransfection experiments of the two receptor cDNAs (which could potentially lead to the formation of four distinct trimeric proteins, whose binding behavior could differ substantially from the homotrimeric proteins) have not yet been reported. Thus, the transfected receptor activities tested to date can ac- 
count for some but not all of the differences in SR ligand binding behavior reported in native macrophages and endothelial cells.

A further complication in dissecting the interaction of SRs with various forms of modified LDL arises from the observation that there may be important species differences in the types of SRs expressed on macrophages (12). Because speciesspecific probes may be required to clarify this problem, it seemed important to generate SR probes that would be useful for both in vitro and in vivo analyses in experimental animals susceptible to atherosclerosis. The previously cloned SR cDNAs derive from species with biological or experimental attributes that impose significant limitations on their utility in such studies. Because the rabbit is widely used as a model for human atherosclerosis, and because recent studies have demonstrated that the oxidative mechanisms postulated to play a role in the formation of modified human LDL are operative in the rabbit as well $(9,21)$, we undertook to isolate the SR from that species. In addition, recent work by Pitas (22), which demonstrated that the degradation of modified LDL in rabbit fibroblasts and SMC could be up-regulated, suggested that the isolation of rabbit SR cDNA probes would be quite useful in determining whether nonreticuloendothelial cells possessed a protein similar, if not identical, to the macrophage SR.

In this article, we report the cloning of the rabbit type I and type II SR cDNAs from an SMC line. This SMC SR appears to be the rabbit homologue of the previously cloned macrophage receptors. These rabbit clones were then used as probes to demonstrate that SMC in culture can be induced to express high levels of SR mRNA, suggesting a mechanism through which these cells could become lipid-laden. Surprisingly, no mRNA could be detected in rabbit venous or bovine aortic endothelial cells, despite these cells' ability to degrade AcLDL. These observations demonstrate that rabbit SR probes will be of use in further investigations into the biology of SR proteins and their role in the pathogenesis of atherosclerosis.

\section{Methods}

Cells. New Zealand rabbit aortic SMC (SMC7) were kindly provided by Dr. George Rothblat (Medical College of Pennsylvania, Philadelphia, PA). SMC7 cells had the characteristic histologic appearance of SMC and stained positively for muscle actin using antibody HHF35 (Enzo Diagnostics, Inc., New York). SMC7 cells were maintained in MEM with $10 \%$ FCS and gentamicin ( $5 \mathrm{mg} /$ liter). The cells used in these experiments were between passages 7 and 12, after explantation. Bovine aortic endothelial cells (a gift of $\mathrm{L}$. Fritze, Massachusetts Institute of Technology, Cambridge, MA) were maintained in DME medium with $10 \%$ FCS and gentamicin $(5 \mathrm{mg} /$ liter $)$. These cells were in passage 36 from explantation and have been characterized by their expression of factor VIII, von Willebrand factor, angiotensin-converting enzyme activity, and AcLDL degradation.

SMC7 cells and bovine aortic endothelial cells were stimulated with phorbol 12-myristate 13-acetate (PMA) at a concentration of $10^{-7} \mathrm{M}$ for $48 \mathrm{~h}$ before RNA isolation or assay for degradation activity. Rabbit venous endothelial cells, in their fourth passage from primary explantation, (generously provided by Dr. L. Birinyi, Brigham and Women's Hospital, Boston, MA) were grown in M-199 media, supplemented with $20 \%$ FCS, $17.5 \mathrm{U} / \mathrm{ml}$ porcine heparin, $100 \mu \mathrm{g} / \mathrm{ml}$ endothelial cell mitogen (Biomedical Technologies, Stoughton, MA), $0.7 \mathrm{mM}$ L-glutamine, $50 \mathrm{U} / \mathrm{ml}$ penicillin $\mathrm{G}, 50 \mu \mathrm{g} / \mathrm{ml}$ streptomycin, and $125 \mathrm{ng} / \mathrm{ml}$ amphotericin B. COS M7 cells were maintained in DME medium with $10 \%$ calf serum and gentamicin ( $5 \mathrm{mg} /$ liter $)$.
$R N A$ isolation. RNA was isolated from rabbit SMC, rabbit venous endothelial cells, and bovine aortic endothelial cells by the method of Chirgwin et al. (23). Polyadenylated RNA was purified using oligo (dT)-cellulose as described (24).

cDNA cloning and sequencing. Two degenerate oligonucleotide primers were synthesized with endonuclease restriction sites and GCrich spacers at their 5 ' termini to facilitate subcloning of polymerase chain reaction (PCR)-amplified products into pBluescript (Stratagene Inc., La Jolla, CA). The sequences of the 5 ' sense primer,

VKF-1 (5'CGCGGGGAATTCGTGAAUTTYGA-

and the $3^{\prime}$ antisense primer,

YGCNCGNTC3'),

\section{T23-1 (5'CGCGGGATCGATGATGACTTGTC-}

CAGAGUTGAA3')

[where $\mathrm{U}$ is $\mathrm{G}$ or $\mathrm{A}, \mathrm{Y}$ is $\mathrm{T}$ or $\mathrm{C}$, and $\mathrm{N}$ is $\mathrm{G}, \mathrm{A}, \mathrm{T}$, or $\mathrm{C}$ ] were based on conserved sequences found in the bovine, human, and mouse $\mathrm{SR}$ cDNAs. The PCR amplification utilized first-strand cDNA synthesized from rabbit lung polyadenylated RNA as previously described (18) in the following buffer: $10 \mathrm{mM}$ Tris- $\mathrm{HCl}\left(\mathrm{pH} 8.3\right.$ at $\left.25^{\circ} \mathrm{C}\right), 50 \mathrm{mM} \mathrm{KCl}$, $3.0 \mathrm{mM} \mathrm{MgCl}, 0.01 \% \mathrm{wt} /$ vol gelatin, $100 \mathrm{nM}$ each dNTP, $5.0 \mathrm{U}$ Amplitaq (Perkin-Elmer Cetus, Norwalk, CT), and 100 pmol of each primer. The reaction was carried out in a DNA thermal cycler (PerkinElmer Cetus) with an initial 2-min denaturation step at $94^{\circ} \mathrm{C}$ followed by 35 cycles of $94^{\circ} \mathrm{C}$ for $60 \mathrm{~s}, 55^{\circ} \mathrm{C}$ annealing for $60 \mathrm{~s}$, and $72^{\circ} \mathrm{C}$ extension for $2 \mathrm{~min}$. The reaction product from this amplification, $\mathrm{f} \mathrm{Rab201}$, was used as a probe for subsequent screening of a cDNA library.

Polyadenylated RNA isolated from PMA-treated rabbit SMC7 cells was used to construct a size-fractionated $(>700 \mathrm{bp}$ ) oligo (dT)-primed cDNA library in Lambda Zap II (Stratagene Inc.) (16). This library was amplified once, and $1 \times 10^{6}$ plaques were screened (hybridization at $42^{\circ} \mathrm{C}$ in $50 \%$ formamide and $6 \times \mathrm{SSPE}$, final washing at $68^{\circ} \mathrm{C}$ in $0.2 \times$ SSC) with random-primed, ${ }^{32} \mathrm{P}$-labeled $\mathrm{f} \mathrm{Rab} 201$ as described (16). All DNA sequencing was performed using the dideoxy chain termination method and Sequenase (U.S. Biochemical Corp., Cleveland, $\mathrm{OH}$ ).

Northern blot analysis. Total and polyadenylated RNA from rabbit and bovine tissues and cultured cells were loaded onto $1 \%$ agarose gels containing $2.2 \mathrm{M}$ formaldehyde and then transferred to supported nitrocellulose membranes (Nitro Pure, Micron Separations Inc., Westboro, MA). After baking, the membranes were hybridized with ${ }^{32} \mathrm{P}$-labeled probe using conditions described in the figure legends for each blot. Autoradiography was performed at $-80^{\circ} \mathrm{C}$ with intensifying screens.

$S R$ degradation assays. The cDNA inserts from the in vivo excised pBluescript plasmids pRABSR1 and pRABSR2, encoding the type I and type II rabbit SRs, respectively, were subcloned into the COS cell expression vector, pCDNA-1 (Invitrogen, San Diego, CA), to create the expression plasmids pXRSR1 and pXRSR2. These expression plasmids and the control plasmid, pCDNA-1, were transfected into COS M7 cells as described by Seed and Aruffo (25). The ability of the transfected cells to degrade ${ }^{125}$ I-AcLDL in the presence and absence of unlabeled competitors was assayed as described (26). Degradation was carried out at $37^{\circ} \mathrm{C}$. All lipoproteins used in these assays were prepared by methods previously detailed (26). Iodination of lipoproteins was accomplished by a modified iodine monochloride reaction (27).

The preparation of SMC and endothelial cells for degradation assays was as follows. On day 1, rabbit SMC7 cells and bovine aortic endothelial cells were lifted from confluent plates with trypsin and set at 125,000 cells per $15-\mathrm{mm}$ well. On day 2 media was removed from the cells and replaced by fresh media that had been either supplemented or not supplemented with $10^{-7}$ M PMA. On day 4, the ability of the cells to degrade ${ }^{125} \mathrm{I}$-AcLDL was assayed. Rabbit venous endothelial cells, grown to confluence in $35-\mathrm{mm}$ dishes, were assayed for SR activity in the same manner. 


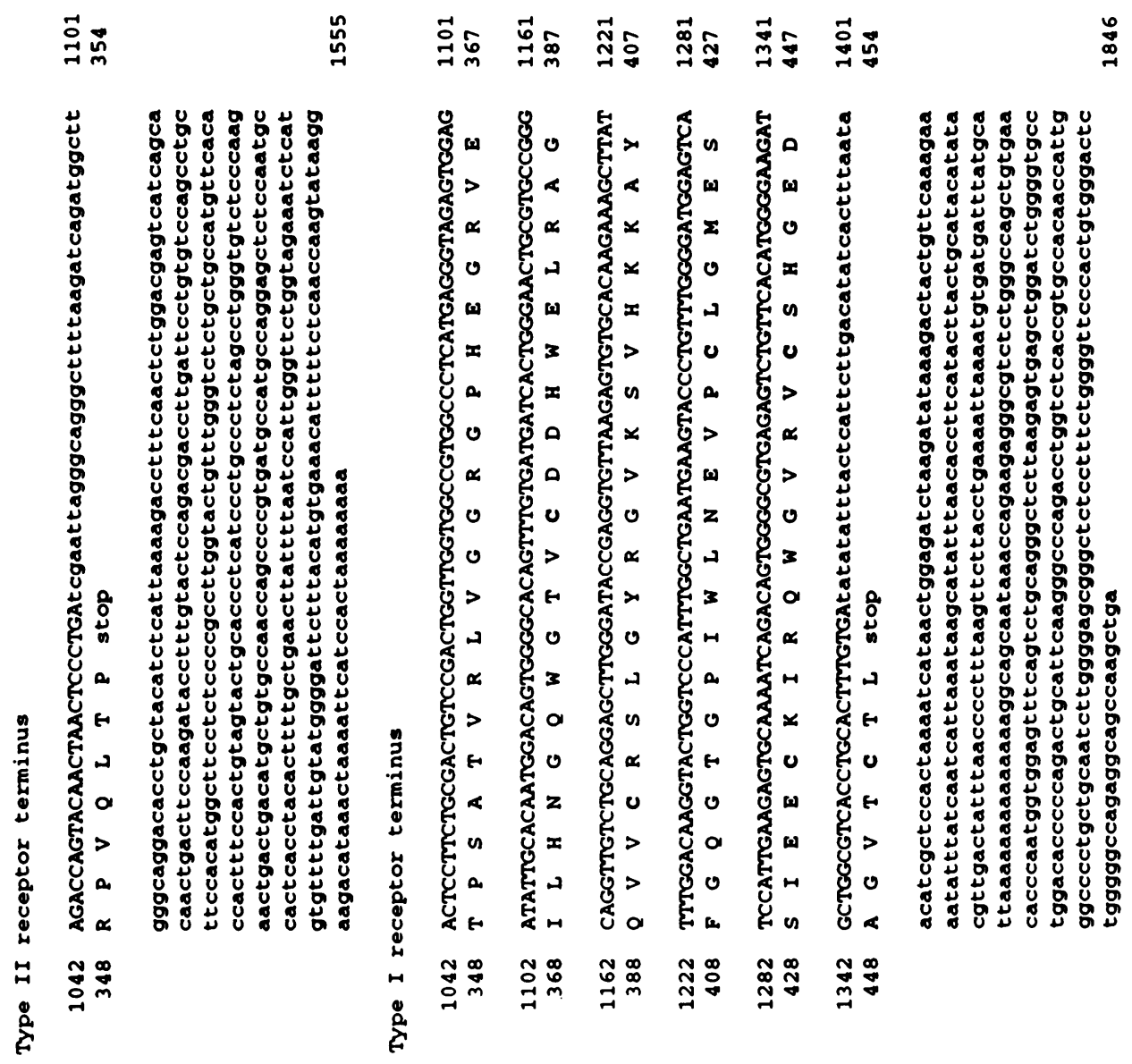

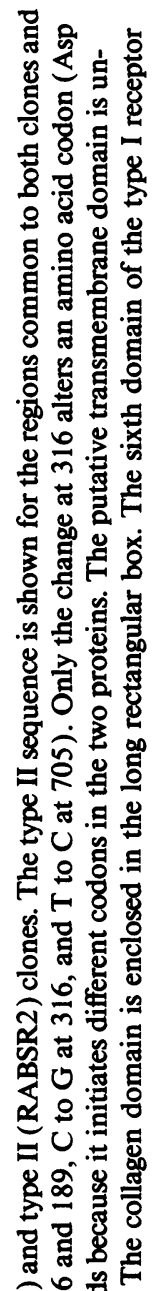

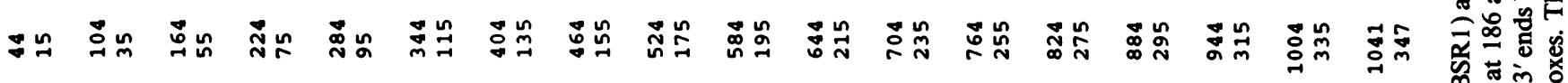

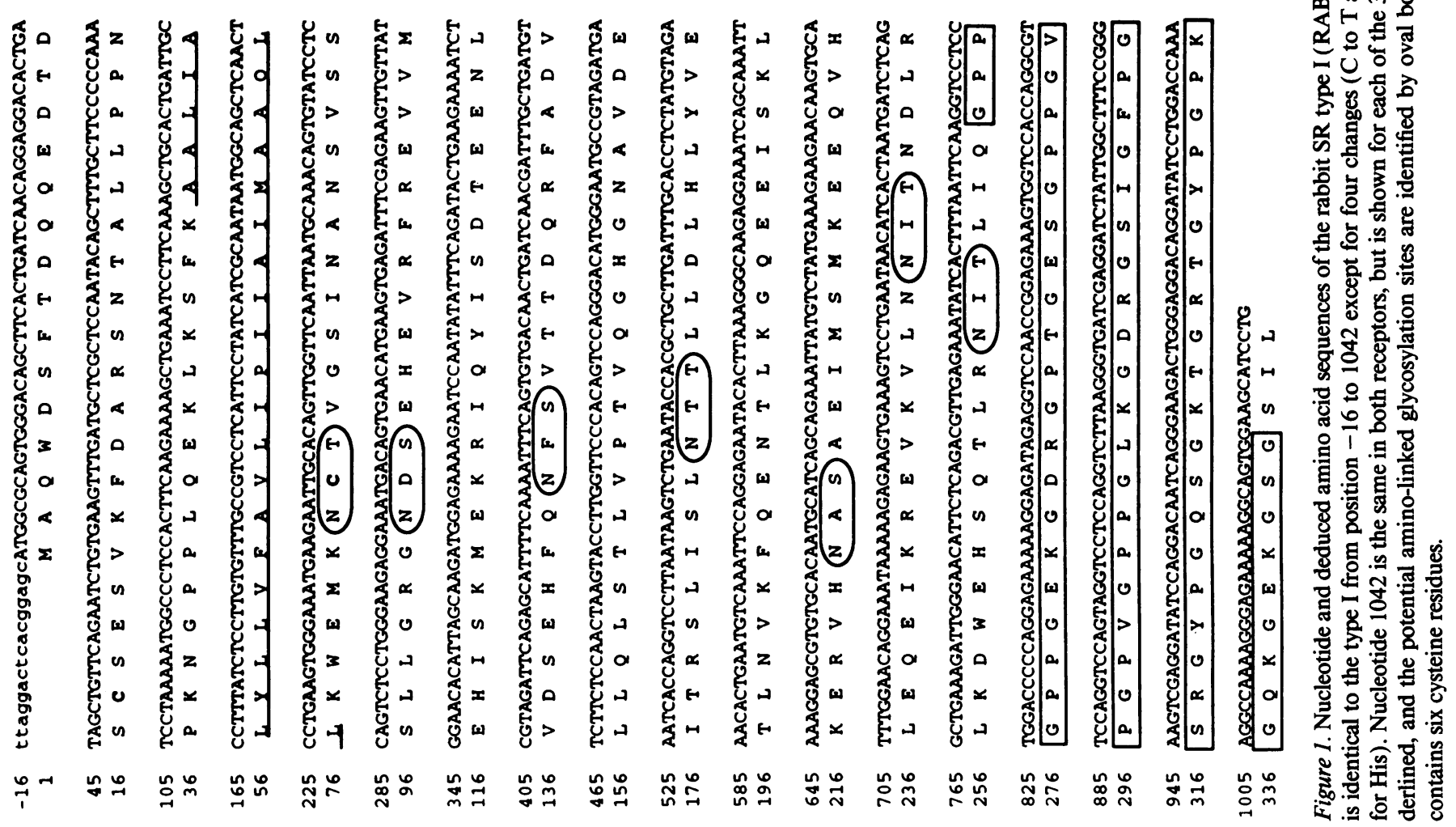




\section{Results}

An 1,100-bp DNA fragment, $f R a b 201$, was initially isolated from a rabbit lung cDNA library using the degenerate PCR primers VKF-1 and T23-1. The sequence of this fragment confirmed its similarity but nonidentity to previously isolated mouse, human, and bovine receptor cDNA sequences. This isolate was radiolabeled and used to screen a Northern blot containing RNA from rabbit tissues and from rabbit SMC that had been treated with $10^{-7} \mathrm{M}$ PMA. The intensity of the hybridizing band from the PMA-treated rabbit SMC prompted us to make a phage cDNA library from this RNA in order to isolate full-length clones devoid of any potential PCR errors. $1 \times 10^{6}$ phage plaques were screened using a ${ }^{32} \mathrm{P}$-radiolabeled 300 -bp fragment derived from the $5^{\prime}$ end of $\mathrm{f}$ Rab201. > 200 plaques hybridized to this probe. Southern blot analysis of the inserts from in vivo excised plasmids were performed, and two clones were selected for further evaluation. Restriction endonuclease mapping and dideoxy DNA sequencing confirmed that these two plasmids, pRABSR1 and pRABSR2, contained inserts (RABSR 1 and RABSR2) encoding the entire coding sequence of the type I and type II SRs, respectively. The sequence of the two clones is given in Fig. 1.

The sequence of RABSR 1 predicts a protein of 454 amino acids, with a calculated $M_{\mathrm{r}}$ of $49,708 \mathrm{D}$. RABSR2's length is 354 amino acids with an $M_{\mathrm{r}}$ of $38,837 \mathrm{D}$. The RABSR $1 \mathrm{cDNA}$ is identical to the RABSR2 isolate from position -16 to 1042 except for four nucleotide changes (Fig. 1, legend). Only the $\mathrm{G}$ to $C$ change at position 316 alters the deduced amino acid sequence; the other differences are in synonymous third codon locations. The change at position 316 results in an aspartate for histidine substitution at amino acid number 106. This amino acid position is not conserved among the other species whose sequences have been determined. Only a single synonymous nucleotide difference was present in the sequences shared by the bovine type I and II cDNA clones, while the human type I and type II cDNA's were reported to be identical in their common domains (16-19). These findings, and the tight linkage of the mapped type I and type II genes in humans and mouse, suggest that the two forms of the cDNA arise from a single gene $(18,19)$. Alternative splicing of mRNA transcribed off of this gene would then account for the differing 3 ' ends. Direct proof of this hypothesis awaits the determination of the structure of the SR gene(s). If there is only one macrophage SR gene, the four nucleotide differences found in the common region shared by the type I and type II rabbit SR cDNAs could arise as a result of allelic variations in this outbred rabbit strain. Reverse transcriptase cloning artifacts are an alternative, though less plausible, explanation. After nucleotide position 1042, the two rabbit cDNA sequences diverge, the type I receptor possessing a longer sixth domain that contains six cysteines.

The rabbit SR clones are highly homologous to the previously cloned SRs of other species. The percent identity of the deduced protein sequence of the rabbit type I to the published type I human, bovine, and mouse receptor sequences are $81 \%$, $73 \%$, and $76 \%$, respectively. The same comparison for the type II receptor reveals identities of $81 \%, 69 \%$, and $73 \%$. When conservative amino acid substitutions are considered matches, the sequence similarities between the different species range from $79 \%$ to $86 \%$. The deduced structures of the rabbit receptors contain the six domains previously predicted from the bovine sequence, i.e., $(a)$ an amino-terminal cytoplasmic tail, $(b)$ a 26-residue transmembrane segment, $(c)$ a spacer region, $(d)$ an $\alpha$-helical coiled coil stalk, $(e)$ a 72-amino acid collagen domain, and $(f)$ a carboxyl-terminal region which differs between the two receptor types. Only the carboxyl-terminal domain of the type II receptors varies significantly in length and sequence among the different species. All seven potential amino-glycosylation sites are preserved among the species, as is the structure of the $\alpha$-helical coiled coil. The human receptor has one fewer Gly-X-Y triplet in its collagen domain than do the other three species, but the rabbit SR receptor collagen segment's composition is most similar to the human's (Fig. 2). In all species, the collagen domain has a high density of positive charges making it an attractive candidate for the binding domain of a receptor whose ligands are polyanionic. The rabbit lung PCR fragment, $\mathrm{fRab201}$, presumed to have derived from an alveolar macrophage, shared $99 \%$ deduced protein sequence identity with the rabbit smooth muscle SR, despite their origins in genetically distinct, outbred New Zealand white rabbits. Thus, though the tissue source for the cloned rabbit cDNAs was SMC, the above data strongly suggest that the receptor cDNAs in pRABSR 1 and pRABSR2 are the rabbit homologues of the previously cloned bovine, mouse, and human macrophage receptors. More detailed analyses will be required to unequivocally establish that only one SR gene encodes these different receptor cDNAs.

To test the function of the two rabbit clones, RABSR 1 and RABSR2 were subcloned into a COS cell expression vector, pCDNA-1, and transfected into COS cells as previously described. The degradation of ${ }^{125}$ I-AcLDL by these transfectants was measured 48-72 $\mathrm{h}$ after the introduction of the DNA into the cells. The results of these experiments are shown in Fig. 3. Both rabbit expression clones conferred degradation activity on the transfected COS cells, while the expression vector lacking receptor inserts did not. The degradation activity had the ligand specificity characteristic of the macrophage SR, i.e., competition of ${ }^{125} \mathrm{I}$-AcLDL degradation by AcLDL and poly I, with no competition by LDL or poly $\mathrm{C}(6)$. The low levels of degradation activity seen in these transfected cells, as compared to that seen in native macrophages, are similar to the

\footnotetext{
bo QGPPGPPGERGDRGPPGQNGI PGFPGLIGTPGLKGDRGISGLP hu QGPPGPPGEKGDRGPTGESGPRGFPGPIGPPGLKGDRGAIGFP ms QGPPGPQGERGDRGLTGQTGPPGAPGIRGI PGVKGDRGQIGFP ra QGPPGPPGEKGDRGPTGESGPPGVPGPVGPPGLKGDRGSIGFP

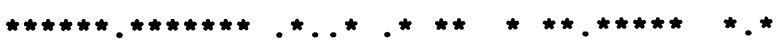

bo GVRGFPGPMGRTGKPGLNGQKGQKGEKGSG

hu GSRGLPG---YAGRPGNSGPRGQKGEKGSG

ms GGRGNPGAPGKPGRSGSPGPKGQKGEKGSVGGS

ra GSRGYPGQSGKTGRTGYPGPKGQRGEKGSG

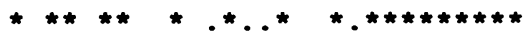

Figure 2. Comparison of the collagen domains from the bovine (bo), human $(h u)$, mouse $(m s)$, and rabbit $(r a)$ scavenger receptors. The Gly-X-Y triplets that have at least one charged residue in the $\mathrm{X}$ or $\mathrm{Y}$ positions are in bold type. The asterisks denote identical residues in all four species; the periods indicate residues where conservative substitutions have been made. The University of Wisconsin Genetics Computer Group program Clustal (36) was used to create the comparison.
} 
A

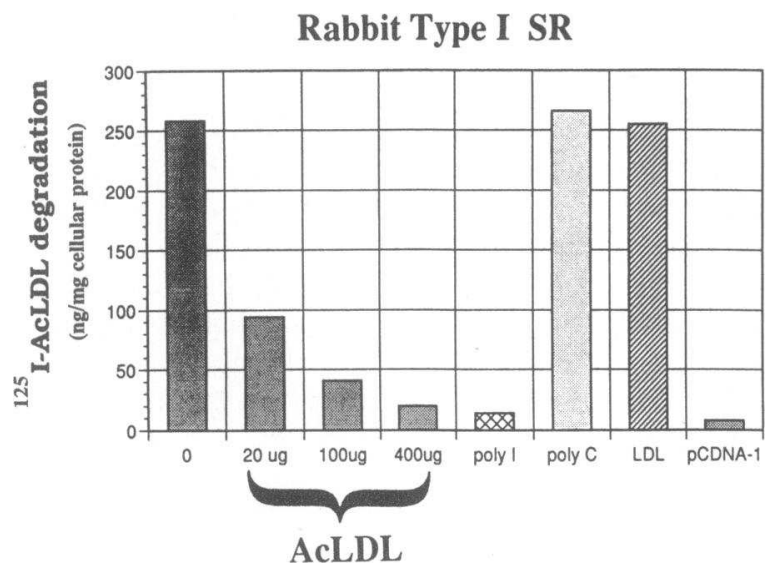

B

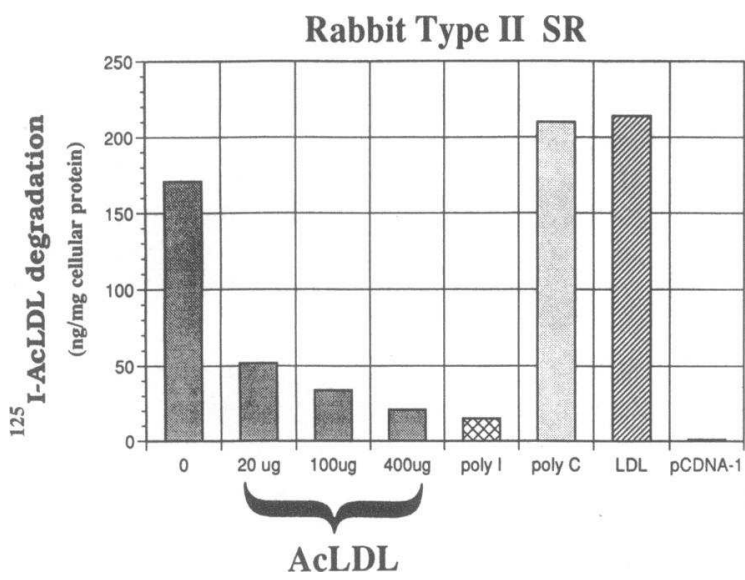

Figure 3. Degradation of $5 \mu \mathrm{g} / \mathrm{ml}$ of ${ }^{125} \mathrm{I}-A c L D L$ by COS cells transfected with $(A) \mathrm{pXRSR} 1$ and $(B) \mathrm{pXRSR} 2$. The concentrations of unlabeled AcLDL competitor are shown on the abscissa. The nonAcLDL competitors were all used at concentrations of $400 \mu \mathrm{g} / \mathrm{ml}$. The pCDNA-1 value represents the degradation activity of COS cells transfected with the expression plasmid lacking any receptor DNA sequences. The transfections and degradations assays represented in $A$ and $B$ were conducted as separate experiments. When a simultaneous transfection and assay of the two clones was performed, pXRSR2 degraded approximately three times more ${ }^{125}$ I-AcLDL than did PXRSR1.

levels of activity seen with the bovine COS cell transfectants $(16,17)$. This observation may reflect differences between $\mathrm{COS}$ cells and macrophages in their inherent lysosomal degradation activity, independent of the receptor, or it may indicate that the native SR environment and structure are not replicated when only homotrimers of either the type I or type II protein can be synthesized. As with previous transfection experiments using the bovine type I and type II receptors, when the rabbit type I and type II receptor degradation activities were compared after simultaneous transfection, the type II protein possessed greater degradation activity (see Fig. 3, legend). This may reflect differences in transfection efficiencies or intracellular receptor processing between the two types of receptor, rather than indicating an intrinsically higher level of activity of the type II protein.
Northern blot analysis of rabbit cell lines was performed using a probe sequence common to the two types of receptor (Fig. 4). RNA from untreated SMCs contained an mRNA that was detected by the SR probe in some preparations and not in others (see Figs. 4 and 5), but after PMA treatment of SMCs, three bands of $1.8,2.8$, and $3.8 \mathrm{~kb}$ in size were easily visualized. Surprisingly, RNA from rabbit venous endothelial cells produced no hybridization signal. In that the possession of SR degradation activity is widely used as a criterion for identifying endothelial cells in primary culture, the failure of these cells to give a hybridizing signal prompted further investigation (28).

Degradation assays were performed using rabbit venous endothelial cells and bovine aortic endothelial cells (Fig. 5). Such bovine cells treated with $10^{-7}$ M PMA were also tested. The level of degradation activity in the endothelial cells was comparable to that seen in the non-PMA-treated SMCs, but PMAtreated SMCs degraded approximately five times more AcLDL than did endothelial cells. PMA treatment did not increase degradation activity in the bovine cells and was not tested in the rabbit endothelial cell line. Neither endothelial cell line had any detectable SR mRNA by Northern blot analysis under the conditions listed in Figs. 4 and 5. The intensity of the hybridization signals demonstrated with von Willebrand factor and actin probes in the endothelial cell lines suggest that RNA degradation was not responsible for the failure to detect SR message. Attempts to immunoprecipitate a bovine SR from [ $\left.{ }^{35} \mathrm{~S}\right]-$ methionine-labeled bovine aortic endothelial cells using a rabbit anti-bovine SR antibody, which can precipitate bovine SR receptors from transfected $\mathrm{CHO}$ cells, were unsuccessful (data not shown).

\section{Discussion}

Macrophage SRs are trimeric proteins whose novel structure has been tightly conserved across a wide evolutionary expanse. The physiologic role of these receptors remains uncertain, but

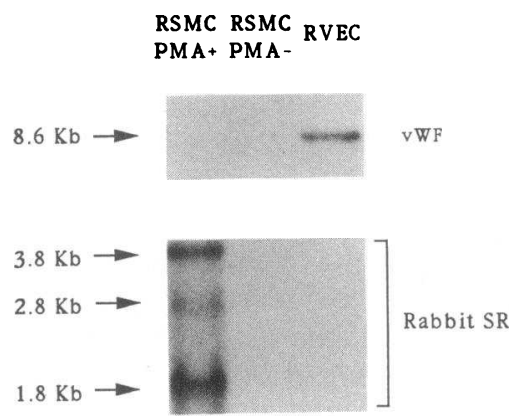

Figure 4. Northern blot of rabbit cell culture lines. Total RNA ( 30 $\mu g$ ) isolated from rabbit venous endothelial cell explants $(R V E C)$ or rabbit aortic smooth muscle cells $(R S M C)$ that had been either treated $(P M A+)$ or not treated $\left(P M A^{-}\right)$with phorbol ester were separated by electrophoresis and blotted onto a nitrocellulose membrane. A fragment of RABSR2 (corresponding to the first 666 nucleotides in

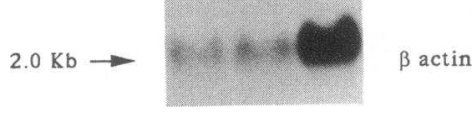
Fig. 1) was radiolabeled with ${ }^{32} \mathrm{P}$ by random-priming and hybridized
to the membrane at $42^{\circ} \mathrm{C}$ in $40 \%$ formamide and $6 \times$ SSPE. The membrane was washed in $2 \times$ SSC and $0.1 \%$ SDS at $48^{\circ} \mathrm{C}$, and was then exposed for $7 \mathrm{~d}$ to Fugi $\mathrm{RX}$ film at $-80^{\circ} \mathrm{C}$ with an intensifying screen. The membrane was subsequently stripped of probe and rehybridized with probes for von Willebrand factor $(\nu W F)$ and $\beta$-actin. 
A

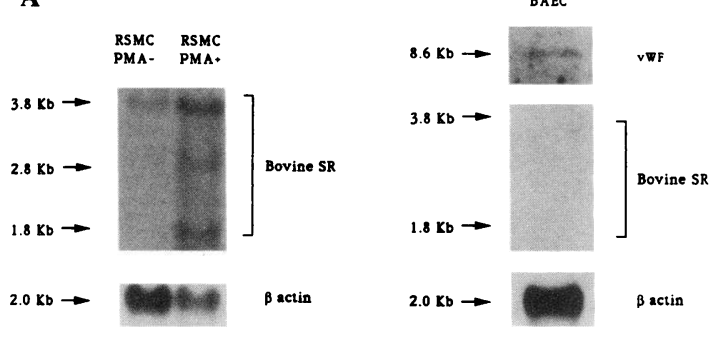

B

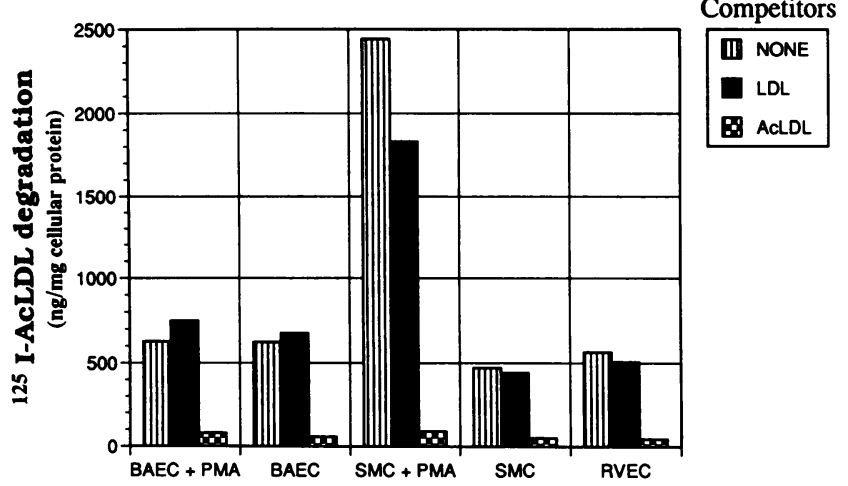

Figure 5. $(A)$ Northern blots and $(B)$ degradation assays of rabbit and bovine cultured cells. $(A)$ Total RNA $(20 \mathrm{mg})$ isolated from rabbit aortic smooth muscle cells ( $R S M C)$ that had been treated (PMA+) or not treated $(P M A-)$ with phorbol ester, and polyadenylated RNA $(5 \mathrm{mg})$ isolated from bovine aortic endothelial cells $(B A E C)$ were electrophoresed on separate gels and blotted onto nitrocellulose membranes. These membranes were then hybridized with ${ }^{32} \mathrm{P}$-labeled strand-specific bovine SR probe (37) at $42^{\circ} \mathrm{C}$ in $40 \%$ formamide and $5 \times$ SSPE. The membranes were washed in $2 \times$ SSC with $0.1 \%$ SDS at $42^{\circ} \mathrm{C}$ and exposed to Kodak XAR film for $8 \mathrm{~d}$ at $-80^{\circ}$ with an intensifying screen. The blots were also probed with radiolabeled cDNAs that encode $\beta$-actin and von Willebrand factor $(v W F)$. (B) Degradation of $5 \mu \mathrm{g} / \mathrm{ml}$ of ${ }^{125} \mathrm{I}$-AcLDL over $5 \mathrm{~h}$ by BAEC, rabbit aortic SMC, and rabbit venous endothelial cells (RVEC) that had been treated with phorbol ester $(B A E C+P M A$ and $S M C+P M A)$ or not treated with phorbol ester ( $B A E C, S M C$, and $R V E C)$. Incubations were performed in the presence or absence of $400 \mu \mathrm{g} / \mathrm{ml}$ of unlabeled LDL or AcLDL.

their ability to bind diverse ligands, particularly modified forms of LDL, has implicated them in the process of atherosclerotic foam cell formation. In this article, we report the cloning of cDNAs encoding the type I and type II scavenger receptor of the rabbit, an animal widely used in experimental models of human atherosclerosis. The predicted amino acid sequences of these clones are $>80 \%$ identical to the human receptors, and the important structural features of the SR identified in the cloning of the bovine receptor are conserved among the species. A comparison of the protein sequences that have been conserved across species points to several domains within the receptor where mutational analysis should yield important functional insights. Once identified, it should be possible to test the significance of functional mutations in vivo in the rabbit using newer gene transfection technologies $(29,30)$. The susceptibility of the rabbit to atherosclerosis, its carriage of the majority of its serum cholesterol in non-HDL lipoproteins, and its relative ease of manipulation as an experimental model afford important advantages for in vivo investigations.

The rabbit receptors described in this paper derived from aortic SMC. Although the initial reports surveying macrophage SR expression stated that SMC lacked significant degradation activity, a number of more recent studies have indicated that low levels of receptor degradation activity are present, in at least some smooth muscle cell lines $(22,31,32)$. Jaakkola and Nikkari (32) demonstrated that a fluorescently sorted population of rabbit SMC, isolated from the aortas of cholesterol-fed rabbits, varied dramatically in their levels of AcLDL degradation activity. This study suggests that SMC from atherosclerotic plaques may not be uniform in their behavior, with respect to SR activity. An intriguing possibility is that some physiologic stimulus to SR expression, analogous to the phorbol ester stimulation we report here, might be present in discrete regions of the arterial intima. If such a stimulus derived from macrophage foam cells, it could account for the time delay usually observed between macrophage and SMC lipid accumulation. Studies are currently underway to try to identify such a stimulus. Whether the smooth muscle foam cell plays any important role in the pathogenesis of plaque development is unclear.

It is possible that the growth conditions used in our studies of SMC led to alterations in gene expression that would not be characteristic of SMC in vivo. The appearance of the cells and their staining by an actin antibody indicate that at least some tissue-specific characteristics of SMC were maintained. In addition, an independently isolated rabbit aortic SMC line has also been demonstrated to possess inducible SR mRNA when probed with our rabbit cDNA probes (Dr. David Benz, Specialized Center of Research on Arteriosclerosis, University of California, San Diego, personal communication). While the study of Jaakkola et al., noted above, provides some support for the presence of SMC scavenger receptor expression in vivo, it cannot be definitively concluded from that work that the uptake of the fluorescently labeled acetyl-LDL was SR dependent. In that previous studies of endothelial, fibroblast, and SMC SR activity have indicated that factors such as cell density and serum concentration can affect the expression of the receptor $(22,33)$, it may be hazardous to use cell culture experiments as a model for the in vivo expression of the receptor. Finally, there may be species differences in expression of SR activity that preclude generalizing the observations in rabbit SMC to SMC of humans or other species. These questions can now be directly addressed through the use of species-specific SR clones as in situ hybridization probes or through the generation of antireceptor antibodies.

Our inability to detect any SR mRNA in rabbit venous or bovine aortic endothelial cells was surprising. The evidence that endothelial cells possess receptor degradation activity is substantial, and this property is widely used in the purification of endothelial cells isolated from vascular tissues $(28,34)$. Although it remains possible that the sensitivity of our Northern blots was insufficient to detect a very low level of SR message, it seems as likely that the endothelial cell SR differs in structure from that of the macrophage receptor. The failure of the bovine aortic endothelial cells to enhance their AcLDL degradation activity in response to phorbol ester stimulation further sug- 
gests this possibility. Alternatively, the action of tissue-specific or species-specific regulatory factors could explain the divergent responses of a common receptor in SMC and endothelial cells. These alternatives are currently being investigated. Finally, endothelial cells isolated from different vascular beds do not all share the same binding behavior with respect to OxLDL and AcLDL, so it is also possible that endothelial cell SRs will not only differ from macrophage SRs, but they may differ among themselves (35). Whether the endothelial cell receptor(s) will be a structurally homologous member of the macrophage SR receptor family awaits purification of the protein or cloning of the cDNA encoding it.

The data presented in this paper establish the structure of rabbit SRs. These proteins are highly homologous to the previously cloned receptors isolated from human, bovine, and murine species. SR mRNA found in rabbit SMC can be up-regulated by phorbol ester stimulation and this increase in message is associated with a fivefold increase in the degradation of modified LDL. The presence of an inducible SR on rabbit SMC suggests a potential mechanism through which these cells could acquire lipids in vivo and subsequently convert to foam cells in the developing atherosclerotic plaque. Rabbit venous and bovine aortic endothelial cells, which possess SR degradation activity, were found by Northern blot analysis not to have mRNA encoding the cloned forms of the macrophage SR. In addition, no SR protein could be immunoprecipitated from bovine aortic endothelial cells. These observations strengthen the hypothesis that a family of SR proteins exists in cells of the reticuloendothelial system. Finally, the cDNA clones described in this study should prove quite useful in studies of experimental atherosclerosis conducted in the rabbit.

\section{Acknowledgments}

We thank Lorna Andersson for her expert technical assistance, Hank Kronenberg for his critical reading of the manuscript, Monty Krieger and Marsha Penman for the use of the anti-bovine SR antibody, and Paul Aftring for many helpful suggestions throughout the course of the work.

This study was supported by a research grant from the National Institutes of Health (RO1-HL-45098 to Dr. Freeman) and a grant-inaid from the American Heart Association (91011940 to Dr. Freeman), with funds contributed in part by the American Heart Association, Massachusetts Affiliate. Dr. Bickel was supported by a training grant awarded to the Endocrine Division at the Massachusetts General Hospital by the National Institutes of Health (T32-DK07028-17).

\section{References}

1. Gerrity, R. G. 1981. The role of the monocyte in atherogenesis. I. Transition of blood-borne monocytes into foam cells in fatty lesions. Am. J. Pathol. 103:181-190.

2. Masuda, J., and R. Ross. 1990. Atherogenesis during low level hypercholesterolemia in the nonhuman primate. I. Fatty streak formation. Arteriosclerosis. 10:164-177.

3. Rosenfeld, M. E., and R. Ross. 1990. Macrophage and smooth muscle cell proliferation in atherosclerotic lesions of WHHL and comparably hypercholesterolemic fat-fed rabbits. Arteriosclerosis. 10:680-687.

4. Stary, H. C. 1990. The sequence of cell and matrix changes in atherosclerotic lesions of coronary arteries in the first forty years of life. Eur. Heart J. 11 (Suppl. E):3-19.
5. Goldstein, J. L., Y. K. Ho, S. K. Basu, and M. S. Brown. 1979. Binding site on macrophages that mediates uptake and degradation of acetylated low density lipoprotein, producing massive cholesterol deposition. Proc. Natl. Acad. Sci. USA 76:333-337.

6. Brown, M. S., S. K. Basu, J. R. Falck, Y. K. Ho, and J. L. Goldstein. 1980. The scavenger cell pathway for lipoprotein degradation: specificity of the binding site that mediates the uptake of negatively-charged LDL by macrophages. $J$. Supramol. Struct. 13:67-81.

7. Brown, M. S., and J. L. Goldstein. 1983. Lipoprotein metabolism in the macrophage: implications for cholesterol deposition in atherosclerosis. Annu. Rev. Biochem. 52:223-261.

8. Wolfbauer, G., J. M. Glick, L. K. Minor, and G. H. Rothblat. 1986. Development of the smooth muscle foam cell: uptake of macrophage lipid inclusions. Proc. Natl. Acad. Sci. USA 83:7760-7764.

9. Yla-Herttula S., W. Palinski, M. E. Rosenfeld, S. Parthasarathy, T. E. Carew, S. Butler, J. L. Witztum, and D. Steinberg. 1989. Evidence for the presence of oxidatively modified low density lipoprotein in atherosclerotic lesions of rabbit and man. J. Clin. Invest. 84:1086-1095.

10. Sparrow, C. P., S. Parthasarathy, and D. Steinberg. 1989. A macrophage receptor that recognizes oxidized low density lipoprotein but not acetylated low density lipoprotein. J. Biol. Chem. 264:2599-2604.

11. Arai, H., T. Kita, M. Yokode, S. Narumiya, and C. Kawai. 1989. Multiple receptors for modified low density lipoproteins in mouse peritoneal macrophages: different uptake mechanisms for acetylated and oxidized low density lipoproteins. Biochem. Biophys. Res. Commun. 159:1375-1382.

12. Ueda, Y. C. Kawai, Y. Nagano, A. Kawashima, and T. Kita. 1991. Scavenger Receptors of Rabbit Peritoneal Macrophages. J. Jpn. Atheroscler. 19:481.

13. Dresel, H. A., E. Friedrich, D. P. Via, H. Sinn, R. Ziegler, and G. Schettler. 1987. Binding of acetylated low density lipoprotein and maleylated bovine serum albumin to the rat liver: one or two receptors? EMBO (Eur. Mol. Biochem. Soc.) J. 6:319-326.

14. Van Berkel, T. J., J. F. Nagelkerke, L. Harkes, and J. K. Kruijt. 1982. Processing of acetylated human low-density lipoprotein by parenchymal and non-parenchymal liver cells: involvement of calmodulin? Biochem. J. 208:493503.

15. Van Berkel T. J., R. Y. B. De, and J. K. Kruijt. 1991. Different fate in vivo of oxidatively modified low density lipoprotein and acetylated low density lipoprotein in rats: recognition by various scavenger receptors on Kupffer and endothelial liver cells. J. Biol. Chem. 266:2282-2289.

16. Kodama, T., M. Freeman, L. Rohrer, J. Zabrecky, P. Matsudaira, and M. Krieger. 1990. Type I macrophage scavenger receptor contains alpha-helical and collagen-like coiled coils. Nature (Lond.). 343:531-535.

17. Rohrer, L., M. Freeman, T. Kodama, M. Penman, and M. Krieger. 1990. Coiled-coil fibrous domains mediate ligand binding by macrophage scavenger receptor type II. Nature (Lond.). 343:570-572.

18. Freeman, M., J. Ashkenas, D. J. Rees, D. M. Kingsley, N. G. Copeland, N. A. Jenkins and M. Krieger. 1990. An ancient, highly conserved family of cysteine-rich protein domains revealed by cloning type I and type II murine macrophage scavenger receptors. Proc. Natl. Acad. Sci. USA. 87:8810-8814.

19. Matsumoto, A., M. Naito, H. Itakura, S. Ikemoto, H. Asaoka, I. Hayakawa, H. Kanamori, H. Aburatani, F. Takaku, H. Suzuki, et al. 1990. Human macrophage scavenger receptors: primary structure, expression, and localization in atherosclerotic lesions. Proc. Natl. Acad. Sci. USA 87:9133-9137.

20. Freeman, M., Y. Ekkel, L. Rohrer, M. Penman, N. J. Freedman, G. M. Chisolm, and M. Krieger. 1991. Expression of type I and type II bovine scavenger receptors in Chinese hamster ovary cells: lipid droplet accumulation and nonreciprocal cross competition by acetylated and oxidized low density lipoprotein. Proc. Natl. Acad. Sci. USA 88:4931-4935.

21. Yla-Herttula S., M. E. Rosenfeld, S. Parthasarathy, E. Sigal, T. Sarkioja, J. L. Witztum, and D. Steinberg. 1991. Gene expression in macrophage-rich human atherosclerotic lesions. 15-lipoxygenase and acetyl low density lipoprotein receptor messenger RNA colocalize with oxidation specific lipid-protein adducts. J. Clin. Invest. 87:1146-1152.

22. Pitas, R. E. 1990. Expression of the acetyl low density lipoprotein receptor by rabbit fibroblasts and smooth muscle cells: up-regulation by phorbol esters. $J$. Biol. Chem. 265:12722-12727.

23. Chirgwin, J. M., A. E. Przybyla, R. J. MacDonald, and W. J. Rutter. 1979. Isolation of biologically active ribonucleic acid from sources enriched in ribonuclease. Biochemistry. 18:5294-5299.

24. Sambrook, J. E. F. Fritsch, and T. Maniatis. 1989. Molecular Cloning, a Laboratory Manual. C. Nolan, editor. Cold Spring Harbor Laboratory, Cold Spring Harbor, NY.

25. Seed, B., and A. Aruffo. 1987. Molecular cloning of the CD2 antigen, the T-cell erythrocyte receptor, by a rapid immunoselection procedure. Proc. Natl. Acad. Sci. USA. 84:3365-3369.

26. Krieger, M. 1983. Complementation of mutations in the LDL pathway of 
receptor-mediated endocytosis by cocultivation of $\mathrm{LDL}$ receptor-defective hamster cell mutants. Cell. 33:413-422.

27. Bilheimer, D. W., S. Eisenberg and R. I. Levy. 1972. The metabolism of very low density lipoprotein proteins. I. Preliminary in vitro and in vivo observations. Biochim. Biophys. Acta. 260:212-221.

28. Voyta, J. C., D. P. Via, C. E. Butterfield, and B. R. Zetter. 1984. Identification and isolation of endothelial cells based on their increased uptake of acetylated-low density lipoprotein. J. Cell Biol. 99:2034-2040.

29. Wilson, J. M., L. K. Birinyi, R. N. Salomon, P. Libby, A. D. Callow, and R.C. Mulligan. 1989. Implantation of vascular grafts lined with genetically modified endothelial cells. Science (Wash. DC). 244:1344-1346.

30. Nabel, E. G., G. Plautz, and G. J. Nabel. 1990. Site-specific gene expression in vivo by direct gene transfer into the arterial wall. Science (Wash. DC). 249:1285-1288

31. Jaakkola, O., O. P. Kallioniemi, and T. Nikkari. 1990. Lipoprotein metabolism of human and rabbit arterial cells in primary culture. Eur. Heart J. 11 (Suppl. E):128-133.
32. Jaakkola, O., and T. Nikkari. 1990. Lipoprotein degradation and cholesterol esterification in primary cell cultures of rabbit atherosclerotic lesions. $\mathrm{Am}$. J. Pathol. 132:457-465.

33. Stein, O., and Y.Stein. 1980. Bovine aortic endothelial cells display macrophage-like properties towards acetylated ${ }^{125}$ I-labelled low density lipoprotein. Biochim. Biophys. Acta. 620:631-635.

34. Yablonka-Reuveni, Z. 1989. The emergence of the endothelial cell lineage in the chick embryo can be detected by uptake of acetylated low density lipoprotein and the presence of a von Willebrand-like factor. Dev. Biol. 132:230-240.

35. Kume, N., H. Arai, C. Kawai, and T. Kita. 1991. Receptors for modified low-density lipoproteins on human endothelial cells: different recognition for acetylated low-density lipoprotein and oxidized low-density lipoprotein. Bio chim. Biophys. Acta. 1091:63-67.

36. Higgins, D. G., and P. M. Sharp. 1989. Fast and sensitive multiple sequence alignments on a microcomputer. Comput. Appl. Biosci. 5:151-153.

37. Hu, N., and J. Messing. 1982. The making of strand-specific M13 probes. Gene. 17:271-277. 